\title{
An Improved Test Method for Energy Consumption and Range of Fuel Cell Vehicles
}

\author{
Dong Hao, ${ }^{1}$ Yanyi Zhang, ${ }^{1}$ Renguang Wang, ${ }^{1}$ Xiaobing Wang, ${ }^{1}$ Kai Zhu, ${ }^{1}$ Jun Li, ${ }^{1}$ \\ and Yongping $\mathrm{Hou} \mathbb{D i D}^{2,3}$ \\ ${ }^{1}$ China Automotive Technology and Research Center Co., Ltd., Tianjin 300300, China \\ ${ }^{2}$ Lab of Clean Energy Automotive Engineering Center, Tongji University, Shanghai 201804, China \\ ${ }^{3}$ School of Automotive Studies, Tongji University, Shanghai 201804, China \\ Correspondence should be addressed to Yongping Hou; yphou@tongji.edu.cn
}

Received 26 August 2019; Accepted 28 May 2020; Published 25 August 2020

Academic Editor: Mostafa Barigou

Copyright (c) 2020 Dong Hao et al. This is an open access article distributed under the Creative Commons Attribution License, which permits unrestricted use, distribution, and reproduction in any medium, provided the original work is properly cited.

At present, there are two main standards, ISO 23828 : 2013 and SAE J 2572-2014, which prescribe the hydrogen consumption test using the pressure method, gravimetric method, and flow method. However, these methods do not meet the test requirements for electric energy consumption and the range of plug-in hybrid fuel cell vehicles (FCVs) which are the main technical considerations in China and Europe. In this paper, a new test method for the hydrogen consumption, electric energy consumption, and range of FCVs is proposed without the use of additional hydrogen supply, measurement instruments, or energy consumption correction, which can improve the operability of the test and avoid the conversion between electric energy and hydrogen. One plug-in hybrid FCV and one nonplug-in hybrid FCV were tested using the proposed method. The results show that the new method meets the requirements of fuel economy test for FCVs with hydrogen consumption rate, electric energy consumption rate, the range for plug-in hybrid FCVs, hydrogen consumption rate, and the range for nonplug-in FCVs.

\section{Introduction}

In the face of challenges such as global energy shortages and environmental pollution, new energy vehicle technology has become the focus of sustainable development in the automotive industry. Fuel cell vehicles (FCVs) are gaining importance among new energy vehicles due to their zeroemission and high-efficiency characteristics and also the diversification of hydrogen resources. These vehicles have been recognized as one of the ideal solutions for energy shortages and climate change [1]. In recent years, extensive resources have been invested in research on the key technologies for fuel cell vehicles, and several FCV passenger cars, such as Toyota's Mirai and Hyundai's NEXO, have come into the markets [2].

In the same way as conventional vehicles, power, economy, handle stability, and safety are essential performance criteria for FCVs. Fuel economy is directly related to the cost in the everyday use of FCVs [3], and it is thus very important to be able to evaluate the fuel economy scientifically. The test methods used to evaluate hydrogen consumption and range of FCVs are mainly based on two standards: ISO 23828 : 2013《Fuel Cell Road Vehicle-Energy Consumption Measurement-Vehicles Fueled with Compressed Hydrogen》 [4] and SAE J 2572-2014《Recommended Practice for Measuring the Exhaust Emissions, Energy Consumption, and Range of Fuel Cell Powered Electric Vehicles Using Compressed Hydrogen》 [5]. In addition, a number of papers have been published concerning the evaluation of hydrogen consumption of FCVs. Yano et al. [6] found that the measurement of hydrogen consumption is strongly influenced by the pulsation frequency and amplitude of $\mathrm{H}_{2}$ supply, and high-accuracy measurements were realized through a series of improvements on the test instruments. The concept of equivalent hydrogen consumption was introduced by Zheng et al. [7] in order to evaluate the impact of the difference between the initial and final states of charge (SOC) of traction battery on hydrogen consumption, which implies that the final SOC of RESS 
(rechargeable energy storage system), such as traction battery and supercapacitor, and the hydrogen consumption of FCVs follow linear relationships. Subsequently, a hybrid system with a fuel cell and a traction battery was optimized by considering the system's size, efficiency, and hydrogen consumption [8]. Similarly, the final SOC of RESS after test does not remain unchanged for different testing cases. Consequently, it is difficult to compare directly and accurately the hydrogen consumption between the different cases. Moreover, Zheng et al. [9] considered the situation where the battery temperature affected the total hydrogen consumption of FCV, as the battery temperature was related to the battery efficiency and was further related to the efficiency of the entire power train.

All the researches mentioned above have provided valuable and significant insight into the evaluation methods of hydrogen consumption. However, the current method has four problems that require further consideration: (a) it is difficult to measure the vehicle's hydrogen consumption with high accuracy; (b) it is impossible to keep the SOC of RESS unchanged before and after the hydrogen consumption test; (c) besides SOC, other factors such as battery temperature and efficiency can also affect hydrogen consumption; (d) no specified test methods for electric energy consumption have been established for plug-in fuel cell hybrid vehicles. Further studies are, therefore, needed to investigate and improve the test methods for energy consumption of FCVs.

A new method for the evaluation of hydrogen consumption and range, based on the analysis of current methods for hydrogen consumption and range of FCVs and considering the features FCVs' power systems, is proposed, and some practical tests are conducted to verify suitability of this method.

\section{Analysis and Application of ISO and SAE Methods in the Hydrogen Consumption of FCVs}

2.1. Brief Introduction to the Related Standards of ISO and $S A E$. The test method for the evaluation of hydrogen consumption for FCVs is provided in ISO 23828:2013 and SAE J 2572-2014 with detailed prescriptions of the ambient conditions, instruments, vehicle conditions, hydrogen consumption measurements, and the correction method for hydrogen consumption. The last two items mentioned above are the core of these two standards.

2.1.1. Test Method for Hydrogen Consumption. Four different measurement methods are described for hydrogen consumption in ISO 23828:2013, which are the pressure method, gravimetric method, flow method, and current method. The current method is based on the assumption that hydrogen is completely converted to electrical current, and this can lead to large errors and is, therefore, not recommended. In SAE J 2572, the pressure method, the gravimetric method, and the flow method are suggested for the measurement of $\mathrm{H}_{2}$ consumption. For these three methods, the additional hydrogen tank or external hydrogen supply systems are needed to supply hydrogen for the test vehicle without using hydrogen from the original tank, as demonstrated in Figure 1.

For the pressure method, the mass of hydrogen consumption, $w$ measured in $g$, is calculated by measuring the gas pressure and temperature before and after the test using

$$
w=m \times \frac{V}{R} \times\left(\frac{P_{1}}{z_{1} \times T_{1}}-\frac{P_{2}}{z_{2} \times T_{2}}\right),
$$

where $V$ is the volume (measured in $\mathrm{L}$ ) of the high-pressure section of the external hydrogen tank, if necessary, accessories; $R$ is the gas constant $(0.0083145 \mathrm{MPa} \cdot \mathrm{L} / \mathrm{mol} \cdot \mathrm{K}) ; P_{1}$ and $P_{2}$ are the pressures, in $\mathrm{MPa}$, of the $\mathrm{H}_{2}$ in the tank at the start and end of the test, respectively; $T_{1}$ and $T_{2}$ are the temperatures, in $\mathrm{K}$, of the gas in the tank at the start and end of the measurement, respectively; $z_{1}$ and $z_{2}$ are the compression factors at $P_{1}, T_{1}$ and $P_{2}, T_{2}$, respectively.

For the gravimetric method, the mass of hydrogen consumption, $w$, measured in $g$, is calculated by the measured gas mass before and after the test using

$$
w=g_{1}-g_{2}
$$

where $g_{1}$ and $g_{2}$ are the mass of the additional hydrogen tank, in $g$, at the start and end of the test, respectively.

For the flow method, the mass of hydrogen consumption, $w$, measured in $g$, is calculated by integrating the mass flow rate over the testing duration using

$$
w=\int_{0}^{t} Q d t
$$

where $t$ is the measurement time and $Q$ is the measured hydrogen mass flow in test, in $\mathrm{g} / \mathrm{s}$.

2.1.2. Linear Correction Method for Hydrogen Consumption. Most hydrogen fuel cell vehicles are currently hybrid FCVs with the configuration of a combination fuel cell stack and traction battery and/or supercapacitor. For nonplug-in hybrid FCVs, in ISO 23828: 2013 and SAE J 2572-2014, the hydrogen consumption needs further correction if the net energy change of RESS is greater than one percent of the total $\mathrm{H}_{2}$ energy consumed in each test cycle, which can be judged using

$$
\left|\frac{\Delta E_{\mathrm{RESS}}}{M \times 120000}\right| \leq 1.0 \%
$$

where $\Delta E_{\mathrm{RESS}}$ is the net energy change of the battery/capacitor system, in J; $M$ is the total mass of the hydrogen consumed over each cycle of the test schedule, in $g$.

According to SAE J 2572-2014, at least four test cycles are needed to collect data in the correction process for obtaining a linear equation between $\mathrm{H}_{2}$ consumption and the net energy change of RESS. Therefore, the preconditioning of RESS becomes very important. A minimum of two tests are conducted after the vehicle's RESS is depleted by preconditioning and a minimum of two tests are conducted after the vehicle's RESS is charged fully by preconditioning. To achieve good results, each data point may be set according to the manufacturer's recommendations or through good engineering judgment. As displayed in Figure 2 , the circle represents the test results for each test, the $x$ - 


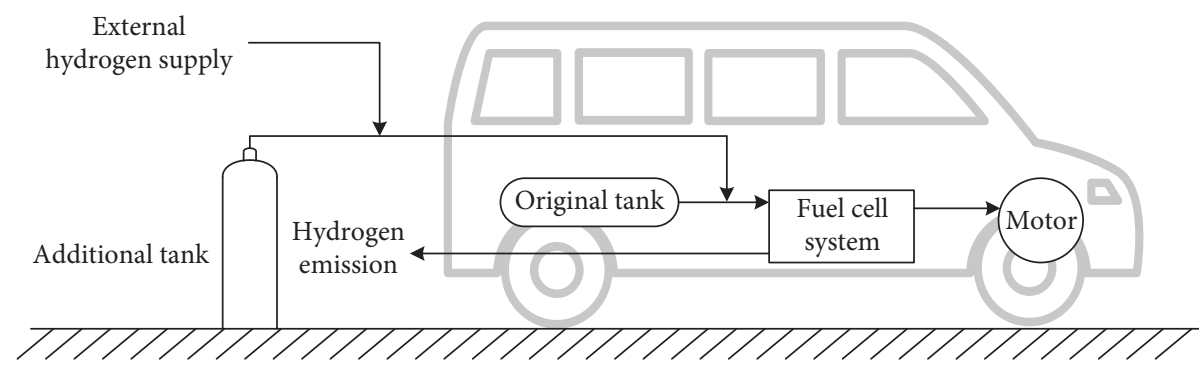

FIGURE 1: Sketch of off-board hydrogen supply.

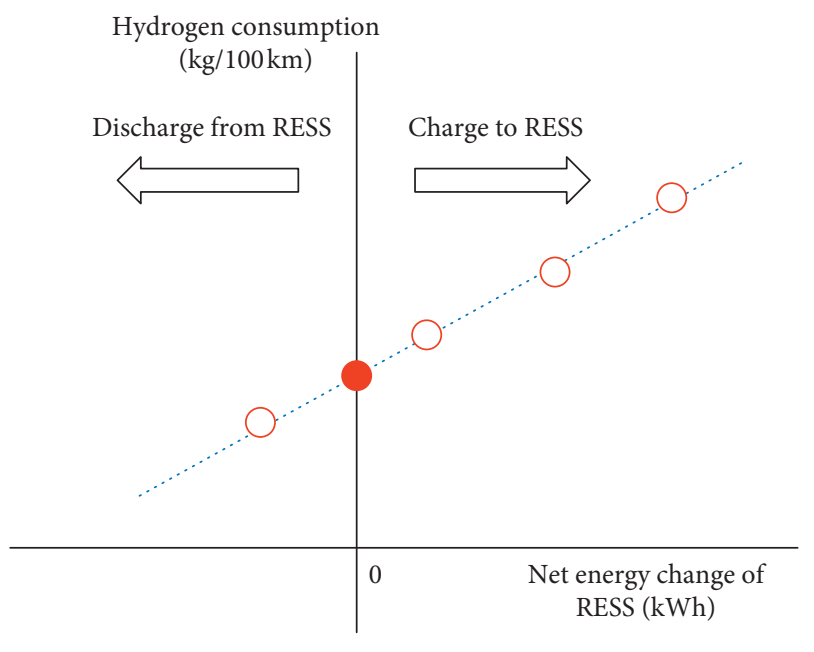

Measured value

...... Linear fit

Corrected value

FIGURE 2: Sketch of corrected $\mathrm{H}_{2}$ consumption.

axis represents the net energy change of RESS, and the $y$-axis shows the $\mathrm{H}_{2}$ consumption. If $\Delta E_{\mathrm{RESS}}$ is greater than zero, it means that the RESS was charged in the test; if $\Delta E_{\text {RESS }}$ is less than zero, it means that RESS was discharged.

The relationship between hydrogen consumption and the net energy change of the RESS can be fitted by a linear equation and then used to determine the value of hydrogen consumption for the case when the net energy change RESS is zero. The acceptance criterion for linearity is as follows: $t$ test with $95 \%$ confidence level and $R$ value greater than or equal to 0.95 .

2.2. Practical Applications of $\mathrm{H}_{2}$ Consumption Methods in ISO 23828 : 2013 and SAE J 2572-2014. The flow method was used to test $\mathrm{H}_{2}$ consumption for hybrid FCVs according to the requirements of ISO and SAE standards. At the temperature of $25^{\circ} \mathrm{C}$, a four-wheel-drive chassis dynamometer and an $\mathrm{H}_{2}$ mass flow meter with accuracy of $1 \%$ were used to conduct the test with the drive schedule of NEDC (New Europe Driving Cycle). The test was repeated over 10 cycles with NEDC, in order to obtain enough samples, and the test results are displayed in Figure 3. The SOC of RESS was adjusted to ensure that its value can take both higher and lower cases.

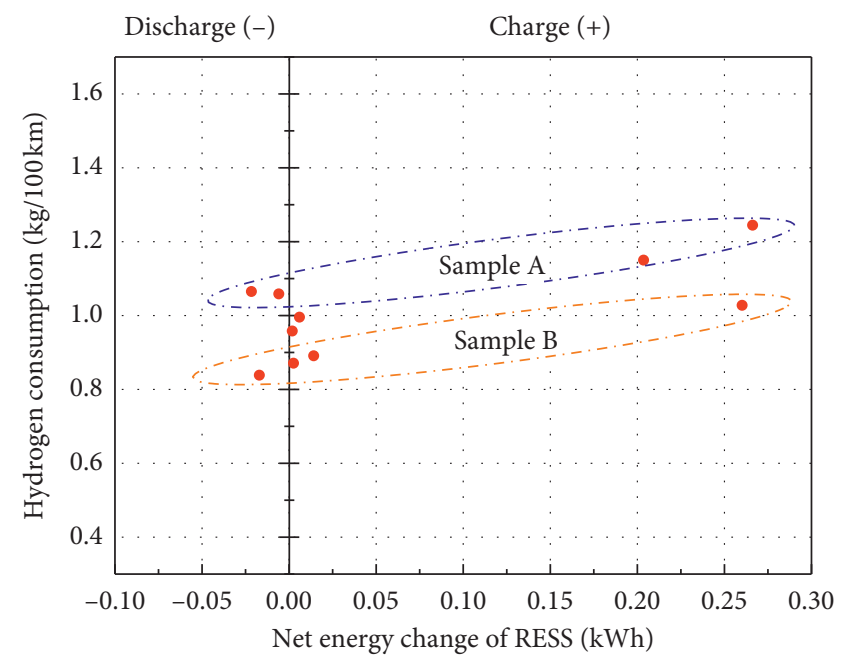

- Measured data of each cycle

FIgURE 3: Test results of $\mathrm{H}_{2}$ consumption of ten cycles.

As displayed in Figure 3, the data has an obviously linear relationship in the charge part of RESS (right side), which is not the case for the data in the discharged part (left side). Among these 10 data, two groups were selected for linear fitting; each group had 4 data points with clearly linear relationships, which meets the data requirements of SAE J 2572-2014.

The data of sample A and sample B were used to obtain the linear fitting equations (5) and (6), respectively, as shown in Figure 4:

$$
\begin{aligned}
& C_{H 2}=0.5725 \times \Delta E_{\mathrm{RESS}}+1.0662, \\
& C_{H 2}=0.6281 \times \Delta E_{\mathrm{RESS}}+0.8662,
\end{aligned}
$$

where $C_{\mathrm{H} 2}$ is $\mathrm{H}_{2}$ consumption per $100 \mathrm{~km}$, in $\mathrm{kg} / 100 \mathrm{~km}$.

Based on the two linear fitting equations above, the $\mathrm{H}_{2}$ consumption and the range were calculated using the method suggested by SAE J 2572-2014. These are listed in Table 1.

From the above process, it can be deduced that the linear fitting of the two data groups can both meet the acceptance criteria: $t$-test with $95 \%$ confidence level and $R$ value greater than or equal to 0.95 . The two different $\mathrm{H}_{2}$ consumption results, after correction using the two linear fitting formulas, were $1.0662 \mathrm{~kg} / 100 \mathrm{~km}$ and $0.8662 \mathrm{~kg} / 100 \mathrm{~km}$, respectively, with the difference amounting to $0.2 \mathrm{~kg} / 100 \mathrm{~km}$. The 


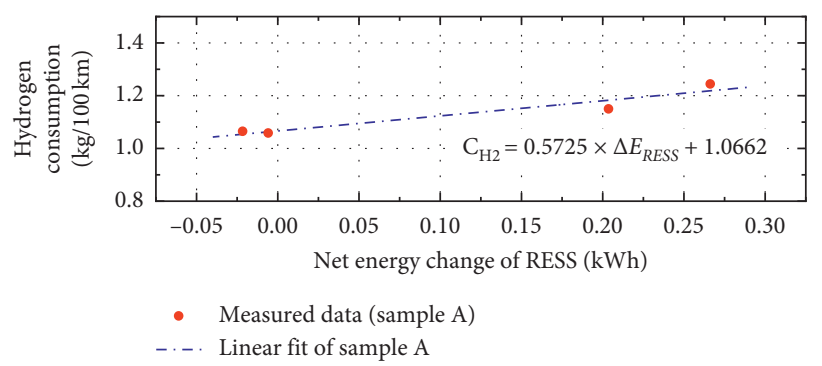

(a)

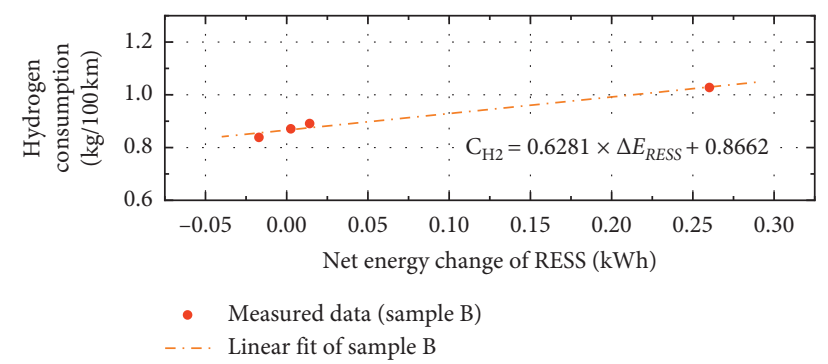

(b)

Figure 4: The linear fitting results of $\mathrm{H}_{2}$ consumption for samples $\mathrm{A}$ and $\mathrm{B}$.

TABLE 1: $\mathrm{H}_{2}$ consumption corrected results and calculated range.

\begin{tabular}{lccc}
\hline Data source & Corrected $\mathrm{H}_{2}$ consumption per $100 \mathrm{~km}(\mathrm{~kg} / 100 \mathrm{~km})$ & Usable fuel amount $(\mathrm{kg})$ & Range $(\mathrm{km})$ \\
\hline Group A & 1.0662 & 4.25 & 398.6 \\
Group B & 0.8662 & 4.25 & 490.6 \\
\hline
\end{tabular}

difference between the two calculated ranges using the usable $\mathrm{H}_{2}$ amount and the $\mathrm{H}_{2}$ consumption was close to $100 \mathrm{~km}$.

2.3. The Suitability Discussion on Methods by ISO and SAE Standards. Given that the two standards, ISO 23828:2013 and SAE J 2572-2014ISO, were released in the year of 2013 and 2014, respectively, their suitability has been changing with the rapid development of FCV technology.

(1) As shown in part 1.2 of this paper, the current method may cause larger errors because of two possible reasons:

(a) The measurement error of $\mathrm{H}_{2}$ consumption: for the flow method adopted in this paper, the fluctuation in the $\mathrm{H}_{2}$ supply can influence the accuracy of the flow meter. Given that the offboard $\mathrm{H}_{2}$ supply system, used in this paper, was constructed according to the method suggested in Annex F of ISO 23828:2013, the maximum accuracy in the $\mathrm{H}_{2}$ mass flow is no more than $1 \%$. The possible factor affecting the inaccuracy by the mass flow measurement can be excluded.

(b) The error caused by the correction method: the correction method by ISO and SAE standards was deduced with an assumption that the linear relationship between $\mathrm{H}_{2}$ consumption of FCV and the net energy change of RESS is correct. This assumption means that, for a certain value of net energy change of RESS, there is a certain value for $\mathrm{H}_{2}$ consumption for the particular FCV. Based on the measurement data displayed in Figure 3, the assumed linear relation is not correct for the following reason: because of the detailed difference between energy management strategies for FCV, the working range of fuel cell stack should be different with different starting SOC of RESS for each test cycle, which can result in different efficiencies in the electricity generation of the fuel cell stack. Therefore, the equivalent net energy change of RESS for different test cycles does not mean equivalent $\mathrm{H}_{2}$ consumption.

(2) The plug-in hybrid FCVs, such as the GLC F-cell of Mercedes-Benz and Roewe 950 fuel cell of SAIC, with higher capacity traction batteries are coming into the market. The evaluation method of $\mathrm{H}_{2}$ consumption by ISO and SAE standards does not suit the measurement of energy consumption for plug-in hybrid FCVs. For plug-in hybrid FCVs with traction battery, the battery can be charged from the grid, and its energy consumption should include both $\mathrm{H}_{2}$ consumption and electric energy consumption. Furthermore, its range should also include the part contributed by the traction battery and must not be simply based on calculations using the amount of usable hydrogen and dividing it by the hydrogen consumption rate.

\section{A New Method for Measurement and Calculation of Energy Consumption and Range of FCVs}

Based on the discussion in part 1, a new method was suggested for obtaining energy consumption and range of FCVs in order to reduce errors in the evaluation of $\mathrm{H}_{2}$ consumption and range caused by the correction method. The new method can satisfy the evaluation of energy consumption for plug-in FCVs.

In this paper, fuel cell vehicles are classified into two types: plug-in FCVs and nonplug-in FCVS. The new method is composed of five main parts: vehicle preparation, test procedure, criteria of end on test, data collection requirements, and data analysis method. The main idea in the new method is that, after vehicle preparation, the range test should be conducted on the chassis dynamometer using 
adaptive driving cycle until the end criteria are met. The data should be collected during the test at the required positions with a certain frequency; after the test, the data is analyzed according to a given procedure for obtaining $\mathrm{H}_{2}$ consumption and electric energy consumption. The details of this new method are discussed as follows.

3.1. Test Vehicle Preparation. Before the test, the test vehicle is prepared according to the following requirements:

(a) Refuel the vehicle. Ensure SOC of $\mathrm{H}_{2}$ tank reaches $99 \% \pm 1 \%$.

(b) For plug-in FCVs, charge the vehicle battery to the full state or meet the manufacturer's requirements. For nonplug-in FCVs, the test personnel should adjust the SOC of traction battery to the highest state or value set by the vehicle manufacturer with the help of engineers from the vehicle manufacturers.

(c) Soak the vehicle at $25 \pm 5^{\circ} \mathrm{C}$ for at least $12 \mathrm{~h}$.

(d) Move the vehicle into position (pushed or towed, not driven) on the dynamometer and restrain.

If the vehicle moves between each step, it shall be pushed to the next test area (without regenerative recharging).

3.2. Test Procedure. The test procedure should meet the following requirements:

(a) The vehicle shall be loaded according to the specification of standards and regulations of local authority. The vehicle should then be started according to the procedure specified by the vehicle's manufacturer and the appropriate test sequence should be applied until the end-of-test criteria are met, when the vehicle should be stopped. The tolerances on speed and time in the test sequence should meet the requirements of standards or regulations.

(b) The stop cases between each drive cycle should not be greater than three times, and the total stop time duration should not be greater than $15 \mathrm{~min}$.

(c) For plug-in FCVs, the RESS should be charged within $30 \mathrm{~min}$ after the end of the test according to the specifications and the electric energy, $E$ in Wh, should be recorded from the grid, and this is the electric energy consumed by the test vehicle.

(d) After soaking the vehicle at $25 \pm 5^{\circ} \mathrm{C}$ for at least $8 \mathrm{~h}$, the vehicle should be moved (without using vehicle power) to an $\mathrm{H}_{2}$ station or other places to refill the $\mathrm{H}_{2}$ tanker to the full state $(99 \% \pm 1 \%)$, and the mass of $\mathrm{H}_{2}$ refilled into vehicle, $m_{\mathrm{H} 2}$ in $\mathrm{kg}$, should be recorded.

(e) Data should be collected and recorded from the start to the end of the test, according to requirements of 2.4 .

3.3. End-of-Test Criteria. There are three criteria, listed as follows, for judging the end of the test sequence. If one of them is satisfied, then the end of the test is reached and the vehicle should be stopped.

(a) If an indication from the onboard instrumentation is shown to the driver to stop the vehicle.

(b) If the speed or the tolerances on speed and time in the test sequence cannot meet the specification, the vehicle should be stopped.

(c) If the pressure of the onboard $\mathrm{H}_{2}$ container drops below 20 bar (includes 20 bar), the vehicle should be stopped.

3.4. Requirements for Data Collection. During the test procedure, the data should be collected in the following format:

(a) Data on the distance, $D$ in $\mathrm{km}$, covered by the vehicle from the start to the end of the test sequence. The time duration, $T$ in $s$, should also be recorded.

(b) The collected data from the tests are shown in Figure 5. For plug-in FCVs, data on the voltage traction battery $\left(U_{\mathrm{BAT}}\right)$, current of traction battery $\left(I_{\mathrm{BAT}}\right)$, output voltage of fuel cell stack $\left(U_{F C}\right)$, and output current of fuel cell stack (IFC) should be recorded. For nonplug-in FCVs, at least two parameters, $U_{\mathrm{BAT}}$ and $I_{\mathrm{BAT}}$, should be collected. The sample frequency should not be below $5 \mathrm{~Hz}$.

(c) The refueled hydrogen mass, $m_{H_{2}}$ in $\mathrm{kg}$, after the test equals the total mass of the hydrogen consumed during the test. For plug-in FCVs, the recharged electric energy, $E$ in $\mathrm{kWh}$, from the grid after the test is the total electric energy from the grid consumed during the test.

\subsection{Data Analysis}

(1) For plug-in FCVs, the data should be analyzed using the following steps:

(a) Based on the collection data of $U_{F C}, I_{F C}$, and $T$, the total output energy, $E_{F C}(\mathrm{kWh})$, from the fuel cell stack can be calculated using

$$
E_{F C}=\frac{\int_{0}^{T} I_{F C} U_{F C} \mathrm{~d} t}{3600 \times 1000}
$$

(b) Based on the collection data of $U_{\mathrm{BAT}}, I_{\mathrm{BAT}}$, and $T$, the net energy change of RESS, $E_{\mathrm{BAT}}(\mathrm{kWh})$, can be calculated using

$$
E_{\mathrm{BAT}}=\frac{\int_{0}^{T} I_{\mathrm{BAT}} U_{\mathrm{BAT}} \mathrm{d} t}{3600 \times 1000} .
$$

(c) The total energy from the RESS and the fuel cell stack, $E_{D}(\mathrm{kWh})$, can be calculated by the addition of $E_{F C}$ and $E_{\mathrm{BAT}}$, obtained from (7) and (8), respectively, using

$$
E_{D}=E_{F C}+E_{\text {BAT }} .
$$




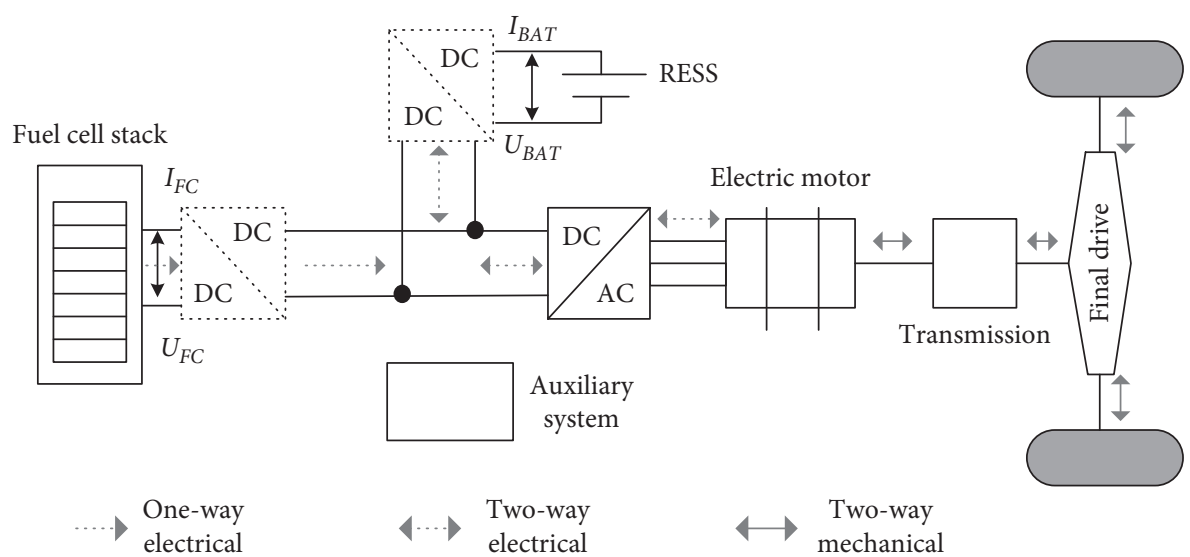

FIGURE 5: Sketch of power system of FCVs.

(d) Based on the results obtained from (7) and (9), the percentage $\left(\eta_{F C}\right)$ of $E_{F C}$ over $E_{D}$ and the percentage $\left(\eta_{\mathrm{BAT}}\right)$ of $E_{\mathrm{BAT}}$ over $E_{D}$ can be calculated by

$$
\begin{gathered}
\eta_{F C}=\frac{E_{F C}}{E_{D}} \times 100 \%, \\
\eta_{\mathrm{BAT}}=\frac{E_{\mathrm{BAT}}}{E_{D}} \times 100 \% .
\end{gathered}
$$

(e) Based on $D$ and $\eta_{F C}$, the range contributed by fuel cell stack, $D_{F C}(\mathrm{~km})$, can be calculated by

$$
D_{F C}=D \cdot \eta_{F C} \text {. }
$$

(f) Based on $D$ and $\eta_{\mathrm{BAT}}$, the range contributed by the traction battery, $D_{\mathrm{BAT}}(\mathrm{km})$, can be calculated by

$$
D_{\mathrm{BAT}}=D \cdot \eta_{\mathrm{BAT}} \text {. }
$$

(g) Based on the measured data $m_{H 2}$ and $D_{F C}$, the $\mathrm{H}_{2}$ computation per $100 \mathrm{~km}, C_{H_{2}}(\mathrm{~kg} / 100 \mathrm{~km})$, can be calculated by

$$
C_{H_{2}}=100 \times \frac{m_{H 2}}{D_{\mathrm{FC}}}
$$

(h) Based on the measured data $E$ and $D_{\mathrm{BAT}}$, the electric energy computation per $100 \mathrm{~km}, C_{E}(\mathrm{kWh} / 100 \mathrm{~km})$, can be calculated by

$$
C_{E}=100 \times \frac{E}{D_{\text {BAT }}} .
$$

Based on the above steps, the economy of plug-in FCVs can be presented with three indexes of range, hydrogen consumption rate, and electric energy consumption rate.

(2) For nonplug-in FCVs, the percentage of the net energy change of RESS over the total hydrogen energy should be calculated first. If the calculated value is less than $3 \%$, then the influence of the traction battery on the range is negligible. Otherwise, the SOC of traction battery should be adjusted to conduct another test.
Based on the investigation on the nonplug-in FCVs, such as Mirai of Toyota, FCX Clarity of Honda, and NEXO of Hyundai, in the market, it was found that all these FCVs are matched with traction batteries with lower capabilities.

(a) With $U_{\mathrm{BAT}}, I_{\mathrm{BAT}}$, and $T$, the net energy change of RESS $E_{\mathrm{BAT}}(\mathrm{kJ})$ can be calculated using

$$
E_{\mathrm{BAT}}=\left|\frac{\int_{0}^{T} I_{\mathrm{BAT}} U_{\mathrm{BAT}} \mathrm{d} t}{1000}\right| .
$$

Compared with plug-in FCVs, the net energy change of nonplug-in FCVs is smaller, and this value can be negative or positive. The absolute value is used in the following calculation.

(b) With known total hydrogen mass, $m_{H 2}$, and lower heating value of hydrogen, the total energy from hydrogen consumed in the range test, $E_{\mathrm{H}_{2}}(\mathrm{~kJ})$, can be calculated by

$$
E_{H_{2}}=m_{H 2} \cdot L H V_{H 2},
$$

where the $\mathrm{LHV}_{\mathrm{H} 2}$ is the lower heating value of hydrogen $(1.2 \times 105 \mathrm{~kJ} / \mathrm{kg})$.

(c) The calculated results from (16) and (17) are then used to calculate the percentage, $\eta_{\mathrm{EBAT} / \mathrm{EH} 2 \text {, }}$ of net energy of RESS over the total energy of hydrogen:

$$
\eta_{\mathrm{EBAT} / \mathrm{EH} 2}=\frac{E_{\mathrm{BAT}}}{E_{H 2}} \times 100 \% .
$$

(d) If $\eta_{\text {EBAT/EH2 }} \leq 3 \%$, then calculate the $\mathrm{H}_{2}$ consumption per $100 \mathrm{~km}, C_{H 2}(\mathrm{~kg} / 100 \mathrm{~km})$, directly using

$$
C_{H 2}=100 \times \frac{m_{H 2}}{D} .
$$

Based on the steps above, the economy of nonplug-in FCVs can be presented using two indexes, which are range and $\mathrm{H}_{2}$ consumption per $100 \mathrm{~km}$, and the range is the measured value in the test instead of being the calculated value. 


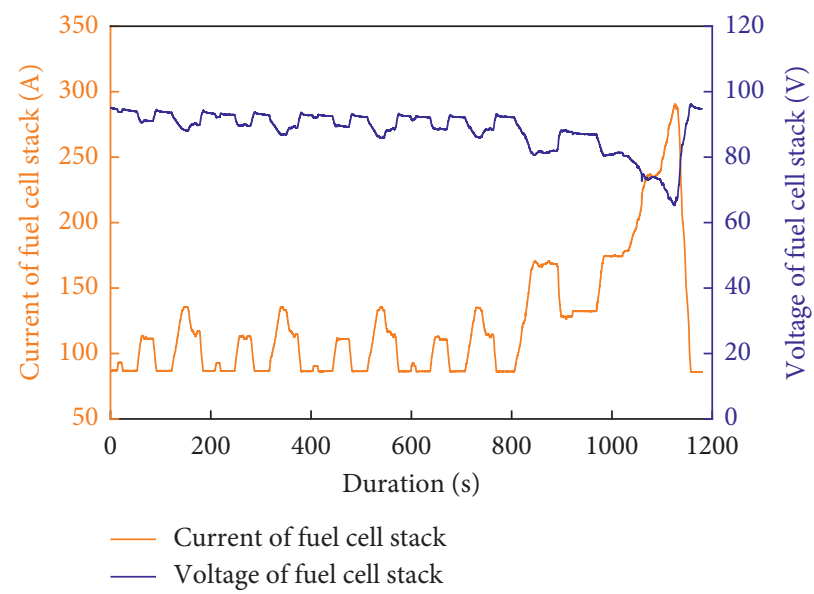

FIgURE 6: The voltage and current curve of fuel cell stack in 17th cycle of the test.

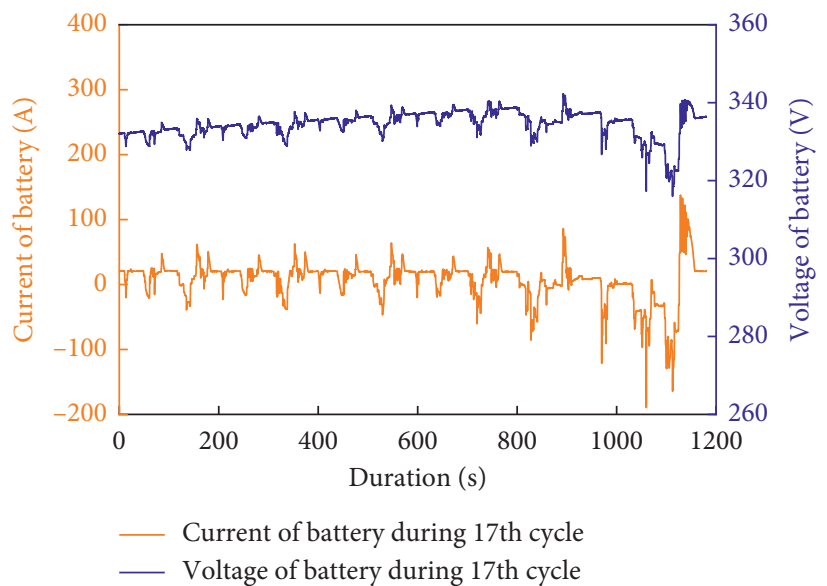

FiguRE 7: The voltage and current curve of traction battery stack in 17th cycle of the test.

\section{Practical Applications of the New Method}

To verify their suitability, one plug-in FCV (passenger car) and one nonplug-in FCV (passenger car) were tested and analyzed using the new method.

4.1. The Test of Plug-In FCV. The test vehicle was a passenger car with a curb weight of $2010 \mathrm{~kg}$, and the vehicle was charged to its full state for traction battery and a refill of $100 \%$ SOC for the $\mathrm{H}_{2}$ tank. The range test was conducted using the drive cycle of NEDC, and the voltage and current of fuel cell stacks and RESS were collected over the whole test process. The data of its 17 th cycle is displayed in Figures 6 and 7 . When the range reached $385.01 \mathrm{~km}$, the indication from the onboard instrument informed the driver to stop the vehicle.

According to the data analysis method of Section 2.5 and based on the five values of range, output energy of fuel cell stack, net energy change of traction battery, mass of $\mathrm{H}_{2}$ consumption, and the electric energy from grid, another five values can be calculated, which are the total energy from the traction battery and fuel cell stack, contribution percentage of traction battery, contribution percentage of fuel cell stack, range contributed by traction battery, and range contributed by fuel cell stack. The related values are listed in Table 2 .

4.2. The Test of Nonplug-In FCV. A nonplug-in FCV passenger car with curb weight of $1950 \mathrm{~kg}$ was used to conduct tests according to the new method. The $\mathrm{H}_{2}$ container of the test car was refilled to its full state and the SOC of its traction battery was adjusted to a higher value. The driving cycle of NEDC was adopted to conduct the range test with measurements of the voltage and current of its traction battery. The data for the 20th cycle is illustrated in Figure 8. When the indicator from the onboard instrument informed the driver to stop, the range was $450.03 \mathrm{~km}$.

The test results are listed in Table 3 . The total energy of hydrogen consumed in the rest was $546,000 \mathrm{~kJ}$ with the total mass of hydrogen consumed at $4.55 \mathrm{~kg}$. The net energy change of traction battery was $4,320 \mathrm{~kJ}$ (or $1.2 \mathrm{kWh}$ ), and the percentage was $0.79 \%$ for the net energy change of traction battery over the total energy of the hydrogen consumed. This percentage means that the range contributed by traction battery was only $3.65 \mathrm{~km}(0.79 \% \times 450 \mathrm{~km})$ and could thus be neglected. According to the new method in this paper, because the condition of $\eta_{\mathrm{EBAT} / \mathrm{EH} 2} \leq 3 \%$ was satisfied, the $\mathrm{H}_{2}$ 
TABLE 2: The measurement and calculation results of $\mathrm{H}_{2}$ consumption and range of the plug-in FCV.

\begin{tabular}{lcc}
\hline Item & Data & Remark \\
\hline Range & $385.01 \mathrm{~km}$ & Measured \\
Output energy of fuel cell stack & $65.6 \mathrm{kWh}$ & Measured \\
Net energy change of traction battery & $16.7 \mathrm{kWh}$ & Measured \\
Mass of $\mathrm{H}_{2}$ consumption & $3.55 \mathrm{~kg}$ & Measured \\
Electric energy from grid & $17.3 \mathrm{kWh}$ & Measured \\
The total energy from traction battery and fuel cell stack & $82.3 \mathrm{kWh}$ & Calculated \\
Contribution percentage of traction battery & $20.3 \%$ & Calculated \\
Contribution percentage of fuel cell stack & $79.7 \%$ & Calculated \\
Range contributed by traction battery & $78.1 \mathrm{~km}$ & Calculated \\
Range contributed by fuel cell stack & $306.9 \mathrm{~km}$ & Calculated \\
$\mathrm{H}_{2}$ consumption per $100 \mathrm{~km}$ & $1.16 \mathrm{~kg} / 100 \mathrm{~km}$ & Calculated \\
Electric energy consumption per $100 \mathrm{~km}$ & $22.1 \mathrm{kWh} / 100 \mathrm{~km}$ & Calculated \\
\hline
\end{tabular}

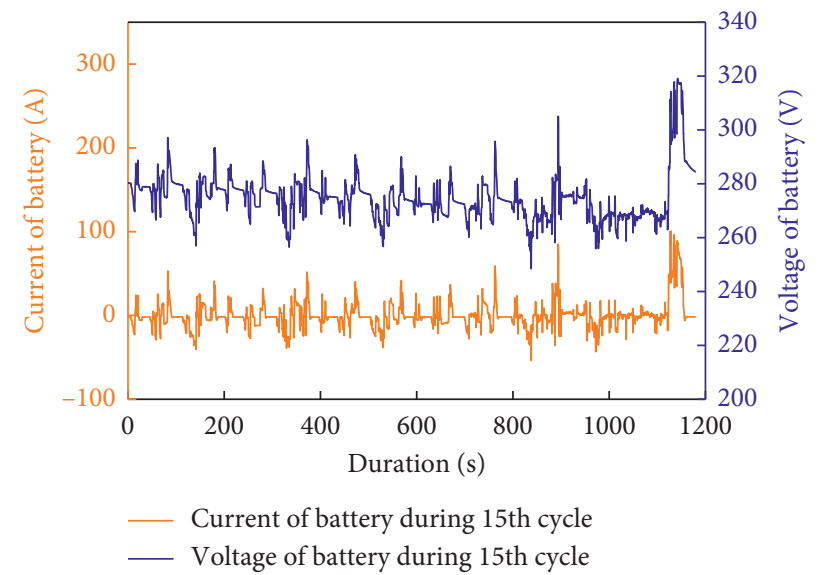

FIGURE 8: The voltage and current curve of traction battery in 20th cycle of the test.

TABLE 3: The results of $\mathrm{H}_{2}$ consumption and range of the nonplug-in FCV passenger car.

\begin{tabular}{lcc}
\hline Item & Value & \multicolumn{1}{c}{ Remark } \\
\hline Range & $450.03 \mathrm{~km}$ & Measured \\
Net energy change of traction battery & $4320 \mathrm{~kJ}(1.2 \mathrm{kWh})$ & Measured \\
Mass of $\mathrm{H}_{2}$ consumed & $4.55 \mathrm{~kg}$ & Measured \\
Percentage of net energy of traction battery over energy of $\mathrm{H}_{2}$ consumed & $0.79 \%$ & Calculated \\
$\mathrm{H}_{2}$ consumption per $100 \mathrm{~km}$ & $1.01 \mathrm{~kg} / 100 \mathrm{~km}$ & Calculated \\
\hline
\end{tabular}

consumption per $100 \mathrm{~km}$ was $1.01 \mathrm{~kg}$, and it could be calculated directly.

\section{Conclusions}

A new method for evaluating the $\mathrm{H}_{2}$ consumption and range was put forward for the complete evaluation of the fuel economy of FCVs, and this method can be used for both plug-in and nonplug-in FCVs. The method overcomes the disadvantages of the methods of ISO and SAE standards, which are not suited to nonplug-in FCVs. The new method does not require off-board $\mathrm{H}_{2}$ supply and measurement instruments such as additional $\mathrm{H}_{2}$ tanks, pressure sensors, temperature sensors, balances with high accuracy, flow meter, and an additional $\mathrm{H}_{2}$ line. The correction process is not needed either, which can improve the operability and suitability of the test method.
The following conclusions can be drawn from the overall process of this new method:

(1) For plug-in FCVs such as GLC FC of MercedesBenz and Roewe 950 FC of SAIC, the current standards do not take two important factors into consideration, namely, the electric energy consumption and the range supported by the traction battery. The new method can solve these problems reasonably well with $\mathrm{H}_{2}$ consumption, electric energy consumption, and range contributed by both $\mathrm{H}_{2}$ and battery.

(2) For nonplug-in FCVs such as the Toyota Mirai, Honda Clarity, and Hyundai NEXO, their range contributions by the traction battery are less than $3 \%$. Therefore, their fuel economy can be presented by $\mathrm{H}_{2}$ consumption and range. 


\section{Data Availability}

The test data used to support the findings of this study are included within the paper.

\section{Conflicts of Interest}

The authors declare that they have no conflicts of interest.

\section{Acknowledgments}

The work was financially supported under the grants of the National Key Research and Development Program of China (Projects nos. 2017YFB0103100 and 2018YFE0105400) and Tianjin Municipal Science and Technology Commission Program (Project no. 17ZXFWGX00040).

\section{References}

[1] A. Veziroglu and R. Macario, "Fuel cell vehicles: state of the art with economic and environmental concerns," International Journal of Hydrogen Energy, vol. 36, no. 1, pp. 25-43, 2011 2011-01-01.

[2] S. Hardman and G. Tal, "Who are the early adopters of fuel cell vehicles?" International Journal of Hydrogen Energy, vol. 43, no. 37, pp. 17857-17866, 2018 2018-01-01.

[3] T. Fletcher, R. Thring, and M. Watkinson, "An Energy Management Strategy to concurrently optimise fuel consumption \& PEM fuel cell lifetime in a hybrid vehicle," International Journal of Hydrogen Energy, vol. 41, no. 46, pp. 21503-21515, 2016.

[4] ISO 23828, Fuel Cell Road Vehicle-Energy Consumption Measurement Vehicles Fueled with Compressed Hydrogen, British Standards Institution, London, UK, 2013.

[5] SAE, Recommended Practice for Measuring the Exhaust Emissions, Energy Consumption and Range of Fuel Cell Powered Electric Vehicles Using Compressed Hydrogen, SAE International, Troy, MI, USA, 2014.

[6] M. Yano, E. Kuroda, H. Tagami, K. Kuroda, and S. Watanabe, "Development of fuel consumption measurement method for fuel cell vehicle - flow method corresponding to pressure pulsation of hydrogen flow," in SAE Technical Paper Series, SAE International, Troy, MI, USA, July 2007.

[7] C. H. Zheng, C. E. Oh, Y. I. Park, and S. W. Cha, "Fuel economy evaluation of fuel cell hybrid vehicles based on equivalent fuel consumption," International Journal of Hydrogen Energy, vol. 37, no. 2, pp. 1790-1796, 2012.

[8] E. Hosseinzadeh, M. Rokni, S. G. Advani, and A. K. Prasad, "Performance simulation and analysis of a fuel cell/battery hybrid forklift truck," International Journal of Hydrogen Energy, vol. 38, no. 11, pp. 4241-4249, 2013.

[9] C. H. Zheng, N. W. Kim, Y. I. Park, W. S. Lim, S. W. Cha, and G. Q. Xu, "The effect of battery temperature on total fuel consumption of fuel cell hybrid vehicles," International Journal of Hydrogen Energy, vol. 38, no. 13, pp. 5192-5200, 2013. 